Hydrol. Earth Syst. Sci. Discuss., 7, 4411-4435, 2010 www.hydrol-earth-syst-sci-discuss.net/7/4411/2010/ doi:10.5194/hessd-7-4411-2010

(c) Author(s) 2010. CC Attribution 3.0 License.
Hydrology and Earth System Sciences Discussions

\title{
Effect of DEM resolution on SWAT outputs of runoff, sediment and nutrients
}

S. Lin ${ }^{1}$, C. Jing ${ }^{1}$, V. Chaplot ${ }^{2}$, X. Yu ${ }^{1}$, Z. Zhang ${ }^{1}$, N. Moore ${ }^{1,3}$, and J. Wu ${ }^{1}$

${ }^{1}$ College of Environmental and Resource Sciences, Zhejiang University, Hangzhou, 310029, China

${ }^{2}$ IRD-BIOEMCO School of Bioresources Engineering and Environmental Hydrology, University of KwaZuluNatal, BoxX01, Scottsville, 3209, South Africa

${ }^{3}$ Department of Geography, Michigan State University, East Lansing, MI, 48823, USA

Received: 6 June 2010 - Accepted: 24 June 2010 - Published: 7 July 2010

Correspondence to: J. Wu (jw67@zju.edu.cn)

Published by Copernicus Publications on behalf of the European Geosciences Union.

HESSD

7, 4411-4435, 2010

Effect of DEM resolution on SWAT outputs

S. Lin et al.

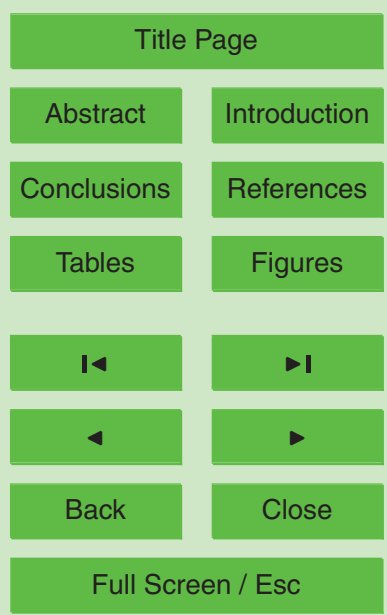

Printer-friendly Version

Interactive Discussion 


\section{Abstract}

Digital Elevation Models (DEMs) have been successfully used in a large range of environmental issues. Several methods such as digital contour interpolation and remote sensing have allowed the generation of DEMs, some of which are now freely avail5 able for almost the entire globe. The Soil and Water Assessment Tool (SWAT) is a widely used semi-distributed model operating at the watershed level and has previously been shown to be very sensitive to the quality of the input topographic information. The objective of this study was to evaluate the impact of DEMs generated from different data sources, respectively DLG5m (local Digital Line Graph, $5 \mathrm{~m}$ interval), 10 ASTER30m (1 arc-s ASTER Global DEM Version 1, approximately $30 \mathrm{~m}$ resolution), and SRTM90m (3 arc-s SRTM Version 4, approximately $90 \mathrm{~m}$ resolution), on SWAT predictions for runoff, sediment, total phosphor (TP) and total nitrogen (TN). Eleven resolutions, from $5 \mathrm{~m}$ to $140 \mathrm{~m}$, were considered in this study. Results indicate that the predictions of TPs and TNs decreased substantially with coarser resampled resolution.

15 Slightly decreased trends could be found in the predicted sediments when DEMs were resampled to coarser resolutions. Predicted runoffs were not sensitive to resampled resolutions. The predicted outputs based on DLG5m were more sensitive to resampled resolutions than those based on ASTER30m and SRTM90m. At original resolutions, the predicted outputs based on ASTER30m and SRTM90m were similar, but the predicted TNs and TPs based on ASTER30m and SRTM90m were much lower than the one based on DLG5m. For the predicted TNs and TPs, which were substantially sensitive to DEM resolutions, the output accuracies of SWAT derived from ASTER30m and SRTM90m could be improved by down-scaled resampling, but they could not improve on finer DEM (DLG5m) at the same resolution. This study helps GIS environmental
HESSD

7, 4411-4435, 2010

\section{Effect of DEM resolution on SWAT outputs}

S. Lin et al.

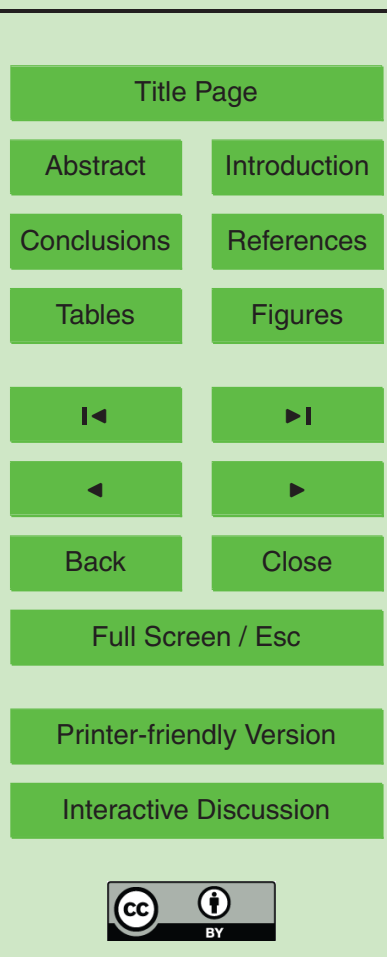




\section{Introduction}

The Soil and Water Assessment Tool (SWAT) (Arnold et al., 1998) is a watershed scale model developed to predict the impact of land management practices on water, sediment, and agricultural chemical yields. SWAT is used in large, complex watersheds

5 taking into account varying soils, land uses/covers, and management conditions over long periods of time. SWAT has been proven to be an effective tool for assessing water resources and nonpoint pollution problems for a wide range of scales and environmental conditions across the globe (Gassman et al., 2007). For example, in China, SWAT is increasingly being used to model hydrological responses to different land use/cover 10 and to climate change (He et al., 2008; Wang et al., 2008; Li et al., 2009a; Ma et al., 2009); to study the effectiveness of conservation practices (Ouyang et al., 2008); and for a wide variety of other water use and water quality applications (Cheng et al., 2007; Li et al., 2009b; Xu et al., 2009; Chen et al., 2010).

Digital Elevation Model (DEM) data play an important role in SWAT. The topographic 15 attributes of the sub-basin, including area, slope, and field slope length are all derived from the DEM. So are channel length, channel slope, channel width, and channel depth, if the channel is automatically generated based on DEM but not previously defined.

In SWAT, the watershed is divided into multiple sub-basins based on topographic 20 features of the watershed. Topographic attributes (slope, field slope length, channel length, channel width, etc.) are calculated at the sub-basin level and then assigned for all Hydrologic Response Units (HRUs) within the sub-basin. HRUs that consist of homogeneous land use, management, and soil characteristics are the basic calculation units. Major model components include climate, hydrology, soil temperature, plant 25 growth, nutrients, pesticides, and land management. Flow, sediment, and other water contaminants yielded from each HRU in a sub-basin are integrated and the resulting loads are routed through channels, ponds and reservoirs to the watershed outlet. SWAT provides two methods for estimating surface runoff volume: the SCS curve num-
HESSD

$7,4411-4435,2010$

\section{Effect of DEM resolution on SWAT outputs}

S. Lin et al.

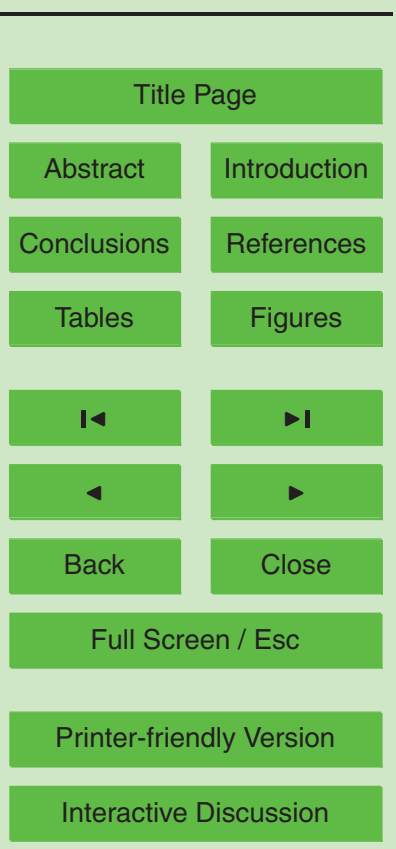


ber procedure (USDA-SCS, 1972) and the Green \& Ampt infiltration method (1911). Erosion caused by rainfall and surface runoff is computed with the Modified Universal Soil Loss Equation (MUSLE) (Williams, 1972). The maximum amount of sediment that can be transported from a reach segment is a function of peak channel velocity. Solu5 ble $\mathrm{N}$ and $\mathrm{P}$ in runoff were estimated as products of the volume of water and average concentrations of $N$ and $P$ in soil layers. Sediment transport of $N$ and $P$ is calculated with a loading function developed by McElroy et al. (1976) and modified by Williams and Hann (1978) for applications to individual runoff events based on the sediment yield in HRUs. A complete description of SWAT theories can be found in Arnold et 10 al. (1998) and Neitsch et al. (2005).

Several studies have been performed to analyze the sensitivity of SWAT outputs on DEM resolutions (Cotter et al., 2003; Chaplot, 2005; Di Luzio et al., 2005; Dixon and Earls, 2009). Cotter et al. (2003) and Chaubey (2005) evaluated the impact of resampled resolutions of DEM $(30 \mathrm{~m}, 100 \mathrm{~m}, 150 \mathrm{~m}, 200 \mathrm{~m}, 300 \mathrm{~m}, 500 \mathrm{~m}$, and $1000 \mathrm{~m})$ on the 15 uncertainties of SWAT predicted flow, sediment, $\mathrm{NO}_{3}-\mathrm{N}$, and total phosphor (TP) transport in Moores Creek watershed $\left(18.9 \mathrm{~km}^{2}\right)$ in Washington County, Arkansas, USA. Their studies showed that DEM resolution affected the watershed delineation, stream network and sub-basin classification in SWAT. A coarser DEM resulted in decreased representation of watershed area, decreased slope, and increased slope length. A de20 crease in DEM resolution resulted in decreased stream flow, sediment, $\mathrm{NO}_{3}-\mathrm{N}$ and TP load predictions with short-term fluctuations. Cotter et al. (2003) recommended minimum DEM data resolution ranged from 100 to $200 \mathrm{~m}$ to achieve less than $10 \%$ error in SWAT output for flow, $\mathrm{NO}_{3}-\mathrm{N}$ and TP predictions.

In the Lower Walnut Creek watershed $\left(21.8 \mathrm{~km}^{2}\right.$, central lowa, USA), Chaplot (2005) 25 evaluated the impact of the mesh size of DEM (from $20 \mathrm{~m}$ to $500 \mathrm{~m}$ ) within SWAT to simulate runoff, sediment, and $\mathrm{NO}_{3}-\mathrm{N}$ loads at the outlet of an agricultural watershed. This study showed that an upper limit to DEM mesh size of $50 \mathrm{~m}$ was required to simulate watershed loads. Increasing the mesh size beyond this threshold did not substantially affect the computed runoff flux but generated prediction errors for nitrogen

\section{HESSD}

7, 4411-4435, 2010

\section{Effect of DEM resolution on SWAT outputs}

S. Lin et al.

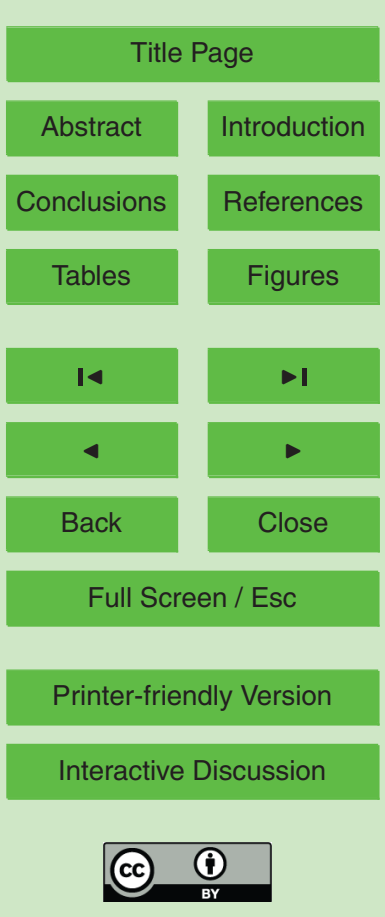


and sediment yields.

Dixon and Earls (2009) compared the SWAT predicted stream flow at the original and resampled DEMs in the Charlie Creek drainage basin $\left(855 \mathrm{~km}^{2}\right)$, located in the Peace River drainage basin of central Florida, USA. The results indicated that SWAT 5 was indeed sensitive to the resolutions of the DEMs: original $90 \mathrm{~m} \mathrm{DEM}$ and $90 \mathrm{~m}$ DEM resampled from $30 \mathrm{~m}$ did not have the same accuracy. Therefore, the effects of resolution could not be ignored and resampling might not be adequate in modeling stream flow using a distributed watershed model.

These past studies have investigated DEMs obtained from ground surveys and/or 10 interpolations of digital contours. In China, high resolution Digital Line Graph (DLG) based on ground survey is used as the standard data and is not publicly accessible. In recent years many new methods for creating DEMs of the Earth's surface have become available, with the release of the space-borne SRTM (Shuttle Radar Topography Mission) and ASTER (Advanced Space borne Thermal Emission and Reflection Radiometer) elevation datasets. The DEM data from these two space missions cover most of the populated regions of the world and are publicly and freely available at a spatial resolution of 3 arc $s$ for SRTM and 1 arc s for ASTER GDEM (ASTER Global DEM). Therefore, there is a need to evaluate the sensitivities of environmental models to these data.

The objective of this study was to compare the SWAT outputs for runoff, sediment, total phosphor (TP), and total nitrogen (TN) using terrain information extracted from the DLG5m (local Digital Line Graph, $5 \mathrm{~m}$ interval), the ASTER30m (1 arc-s ASTER GDEM Version 1, approximately $30 \mathrm{~m}$ resolution), and the SRTM90m (3 arc-s SRTM Version 4 , approximately $90 \mathrm{~m}$ resolution). Different resolutions, from $5 \mathrm{~m}$ to $140 \mathrm{~m}(5 \mathrm{~m}, 10 \mathrm{~m}$, $20 \mathrm{~m}, 30 \mathrm{~m}, 40 \mathrm{~m}, 60 \mathrm{~m}, 80 \mathrm{~m}, 90 \mathrm{~m}, 100 \mathrm{~m}, 120 \mathrm{~m}$, and $140 \mathrm{~m}$ ) were considered in this study.

\section{HESSD}

7, 4411-4435, 2010

\section{Effect of DEM resolution on SWAT outputs}

S. Lin et al.

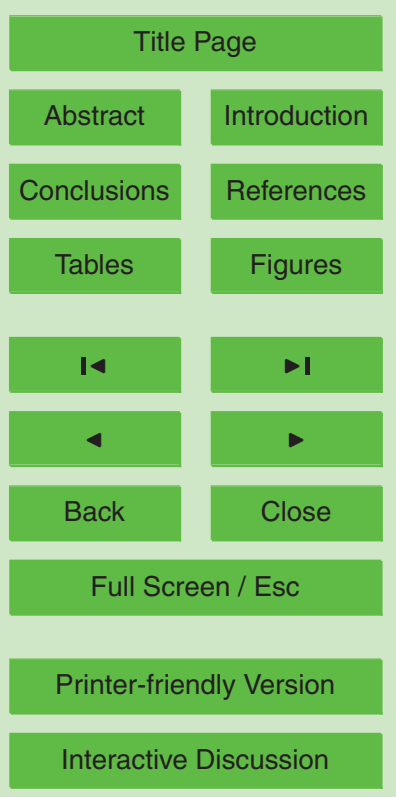




\section{Methodology}

\subsection{Description of the watershed}

HESSD

The study area is located in the Xiekengxi River watershed, an $81.7 \mathrm{~km}^{2}$ watershed in Lin'an City, Zhejiang Province, China (Fig. 1). Mountains dominate most parts of the 5 watershed. The watershed's minimum, maximum, mean, and standard deviation (SD) of altitude above sea level based on DLG5m was $181.2 \mathrm{~m}, 1470.0 \mathrm{~m}, 713.4 \mathrm{~m}$, and $235.5 \mathrm{~m}$, respectively. Major land use within the watershed is mixed forest, accounting for $96 \%$ of total area. Within the watershed there are six species of soil: $61.1 \%$ is Mountain Yellowish Clayey Soil with moderate infiltration rate; $36.6 \%$ is Yellowish Red

10 Soil with high infiltration rate; the rest account for only $2.2 \%$ of the total watershed area (Wei, 1993). The Xiekengxi River watershed is a sub-basin of the Tiaoxi River watershed. The Tiaoxi River flows to the Taihu Lake, which is the third largest freshwater lake in China and was noted world-wide for the eutrophication incident in summer 2007, when millions of people, whose drinking water was supplied from the Taihu Lake, lacked potable water for several weeks.

\subsection{Input data for SWAT modeling}

The following data were collected for this study.

(1) DEM data from three sources: included local DLG, ASTER GDEM, and SRTM.

DLG5m was vector format data of 1: 10000 DLG provided by the Bureau of Survey and Mapping of Zhejiang Province, China. DLG5m was of $5 \mathrm{~m}$ interval contour lines, which was different from ASTER30m and SRTM90m that were grid format. The resolution accuracy of DLG5m is approximately $5 \mathrm{~m}$. TIN (Triangular Irregular Networks) format DEM was generated from the original contour lines before resampling to different resolution DEMs.

25 ASTER GDEM is a new global 1 arc s elevation dataset that was released in June 2009 by METI (Ministry of Economy, Trade and Industry), Japan and NASA (National

\section{Effect of DEM resolution on SWAT outputs}

S. Lin et al.

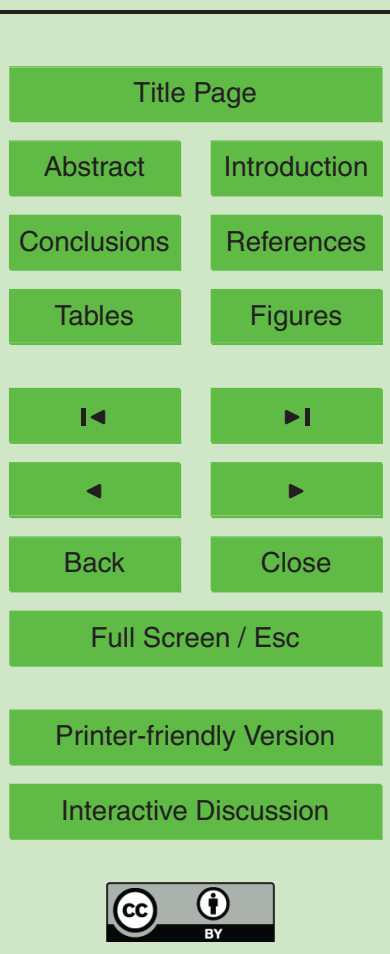


Aeronautics and Space Administration), USA. The ASTER GDEM covers land surfaces between $83^{\circ} \mathrm{N}$ and $83^{\circ} \mathrm{S}$. The data used to produce the GDEM were from VNIR (Visible and Near Infrared Radiometer) Band 3 N (0.76-0.86 $\mu \mathrm{m}$ wavelengths). Pre-production estimated accuracies for this global product were $20 \mathrm{~m}$ at $95 \%$ confidence for vertical data and $30 \mathrm{~m}$ at $95 \%$ confidence for horizontal data (at a $90 \%$ confidence level, these equated to $16.8 \mathrm{~m}$ vertical error and $26.3 \mathrm{~m}$ horizontal error). (http://www.ersdac.or.jp, accessed on 5 May 2010)

The data set of ASTER30m in the study area was downloaded from the website (http://www.gdem.aster.ersdac.or.jp/search.jsp, accessed on 10 January 2010). It was 10 the first version of ASTER GDEM data.

SRTM is the result of a collaborative effort by NASA, USA, the National Imagery and Mapping Agency (NIMA), USA, the German space agency, and Italian space agency. The mission was launched on 11 February 2000 aboard the Space Shuttle Endeavour. Data were collected using two interferometers, C-band and X-band systems, which cover most land regions between $60^{\circ} \mathrm{N}$ and $56^{\circ} \mathrm{S}$ at 1 arc $\mathrm{S}$ resolution. The absolute vertical and horizontal accuracy of 1 arc s SRTM (SRTM1) was reported to be $16 \mathrm{~m}$ and $20 \mathrm{~m}$ (at $90 \%$ confidence). The 3 arc s (SRTM3, about $90 \mathrm{~m}$ resolution) was created by $3 \times 3$ averaging of the SRTM1 data. Following the first release of a research-grade SRTM dataset in 2004, a variety of post-processed releases were available. (http: //csi.cgiar.org, accessed on 5 May 2010)

In this study, the latest post-processed SRTM Version 4, released by the Consortium for Spatial Information (CSI) of the Consultative Group of International Agricultural Research (CGIAR), was selected for its significant improvement over previous releases, and was downloaded from the website (http://srtm.csi.cgiar.org/SELECTION/ inputCoord.asp, accessed on 10 January 2010).

All the DEMs needed to be resampled to different resolutions, including $5 \mathrm{~m}, 10 \mathrm{~m}$, $20 \mathrm{~m}, 30 \mathrm{~m}, 40 \mathrm{~m}, 60 \mathrm{~m}, 80 \mathrm{~m}, 90 \mathrm{~m}, 100 \mathrm{~m}, 120 \mathrm{~m}$, and $140 \mathrm{~m}$, where $5 \mathrm{~m}, 30 \mathrm{~m}$, and $90 \mathrm{~m}$ was the original resolution for DLG5m, ASTER30m, and SRTM90m, respectively. The resampling method was bilinear interpolation. The edge of each DEM was $1 \mathrm{~km}$ out
HESSD

7, 4411-4435, 2010

\section{Effect of DEM resolution on SWAT outputs}

S. Lin et al.

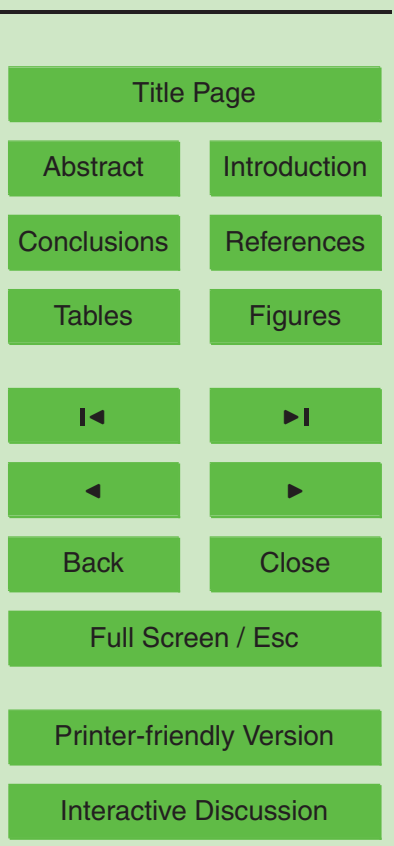


of the watershed boundary, so that the watershed boundary definition for each DEM would not be affected by edge grids. Figure 1 shows the shaped terrains of original resolution DEMs of DLG5m, ASTER30m and SRTM90m.

(2) The land use/cover in 2008 was interpreted from AVNIR-2 (Advanced Visible and 5 Near Infrared Radiometer type 2) images of ALOS (Advanced Land Observing Satellite) with $10 \mathrm{~m}$ resolution.

(3) The soil map was vectorized from 1:50 000-scale soil maps based on the Second National Soil Survey in China. Soil physical and chemical characteristics referred to Wei (1993).

10 (4) Three years (2006-2008) of daily weather gauge data (precipitation, temperature, solar radiation, wind speed, and relative humidity) were provided by Weather Service of Zhejiang Province, China.

\subsection{Model running}

SWAT2005 (available on website http://swatmodel.tamu.edu, accessed on 29 January 2010) was used in this study. In SWAT, the watershed is divided into sub-basins based on the topographic features of the watershed derived from DEM to preserve the natural flow paths, boundaries, and channels required for realistic routing of water, sediment and chemicals. When evaluating the uncertainties of SWAT outputs on DEM resolution, it is necessary to examine the uncertainties of watershed topographic parameters as 20 SWAT inputs. Therefore the following topographic attributes were compared in this study: mean slope gradients of sub-basin, sub-basin areas, mean field slope lengths of sub-basin, reach lengths of sub-basin, reach slopes of sub-basin, reach widths of sub-basin, and reach depths of sub-basin. Because more than one sub-basin was in the watershed, to simplify the comparison, all the watershed topographic attributes were averaged, weighted by the sub-basin areas. Runoff, sediment, TP and TN were the model outputs of interest. Runoff and sediment could be read from the SWAT output file directly. TP consisted of organic phosphorus and mineral phosphorus transported by water out of the watershed outlet. TN consisted of organic nitrogen, nitrate, nitrite,
HESSD

$7,4411-4435,2010$

\section{Effect of DEM \\ resolution on SWAT outputs}

S. Lin et al.

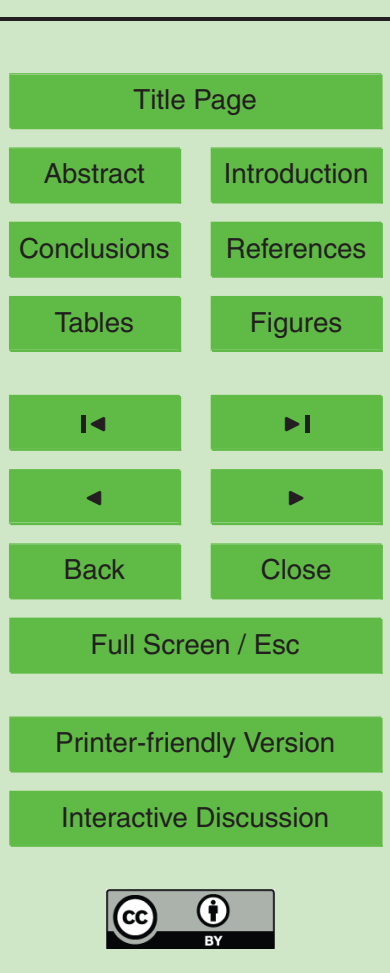


and ammonium transported by water out of the watershed outlet.

SWAT was run in a geographic information system (GIS) interface: ArcSWAT2.3.4 (available on website http://swatmodel.tamu.edu, accessed on 29 January 2010). ArcSWAT is a complete preprocessor, interface and post processor of SWAT. Without leav5 ing the user-friendly ArcGIS environment, users are provided with a complete set of tools for watershed delineation, definition and editing of the hydrological and agricultural management inputs, running, and calibration of the model (Di Luzio et al., 2004). ArcSWAT2.3.4 was used to derive model parameters from GIS layers to create parameter files for SWAT.

10 The uncertainties in SWAT outputs due to different DEM resolutions were assessed by running the model at 11 different DEM resolutions $(5 \mathrm{~m}, 10 \mathrm{~m}, 20 \mathrm{~m}, 30 \mathrm{~m}, 40 \mathrm{~m}$, $60 \mathrm{~m}, 80 \mathrm{~m}, 90 \mathrm{~m}, 100 \mathrm{~m}, 120 \mathrm{~m}$, and $140 \mathrm{~m}$ ) for each DEM from different data sources (DLG5m, ASTER30m and SRTM90m), keeping other simulation conditions constant. These conditions included: (1) the same other input data, e.g. land use, soil, climate,

pond, reservoir and land management; (2) drainage area of 800 ha for stream definitions to produce the same number of sub-basins as far as possible and stream networks close to the real one; (3) the same HRUs definition thresholds of land use/cover $(20 \%)$, soil $(10 \%)$ and slope $(20 \%)$, recommended by Winchell et al. (2005), to eliminate minor land uses, soils and slopes in HRUs; and (4) the same other default parameters (Winchell et al., 2005).

The SWAT running results and the topography parameter tables derived from watershed delineations were saved in the SWAT project data bases for each run. The covered period of the model was 2006 to 2008, but only the annual outputs of 2008 were analyzed to avoid errors in the model's warm-up period. There were 33 runs and 396 variables involved. VBA (Visual Basic for Applications) programming was used to help data retrieval from the model data bases.

\section{HESSD}

$7,4411-4435,2010$

\section{Effect of DEM resolution on SWAT outputs}

S. Lin et al.

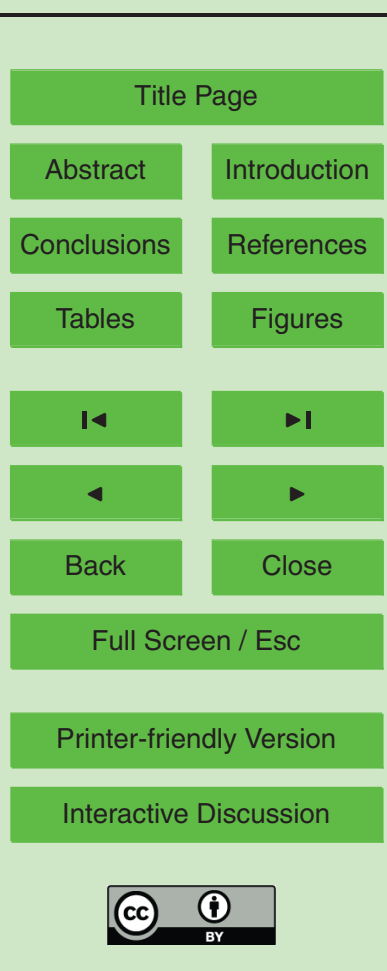




\subsection{Quantification of model uncertainties due to different DEM resolutions}

The uncertainties of watershed delineations and model outputs due to different DEM resolutions were quantified as relative error (RE). This was defined as

$\mathrm{RE}(\%)=100 \times\left(P_{X}-P_{5}\right) / P_{5}$.

5 Where $P_{x}$ was any of the watershed delineations or model outputs based on different resolution DEMs, and $P_{5}$ was the corresponding base value used for comparison which was derived from the finest DEM (DLG5m) with $5 \mathrm{~m}$ resolution, and was assumed to be the best value.

Calibration for each run was not necessary in this study, because even with the 10 best possible model calibration for each run at different resolution, model errors solely due to DEM inputs could not have been isolated. Instead of using measured watershed response data, the best possible model predicted value, $P_{5}$, was used to calculate RE at different resolutions. This approach not only could isolate the uncertainty in the model due to DEM resolution, but also could make the results of watershed delineations or

\section{Results}

\subsection{Terrain characteristics and estimated stream network characteristics}

To understand the effect of DEM resolution on SWAT outputs, the DEM-based watershed terrain characteristics were studied. Results showed that the mean slopes were sensitive to resampled DEM resolution (Fig. $2 b$ ). The RE variation of mean slope
HESSD

$7,4411-4435,2010$

\section{Effect of DEM resolution on SWAT outputs}

S. Lin et al.

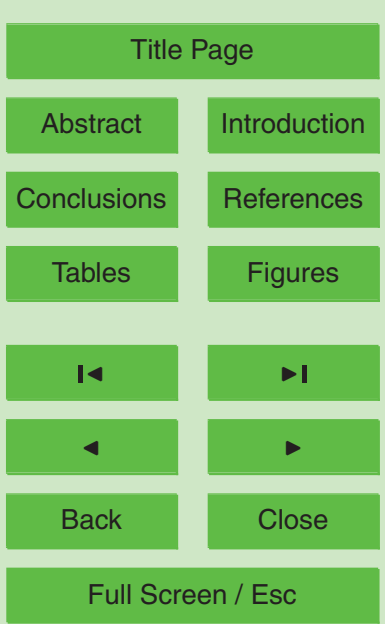

Printer-friendly Version

Interactive Discussion 
variations due to resampled resolutions of DLG5m, ASTER30m, and SRTM90m, was $40.0 \%, 12.8 \%$, and $13.2 \%$, respectively (Table 1 ). At the original resolutions, the mean slopes calculated from ASTER30m and SRTM90m were lower than that calculated from DLG5m by $32.1 \%$ and $37.2 \%$, respectively (Table 1 ).

5 A dramatic change of slopes could cause substantial variations in field slope lengths in ArcSWAT watershed delineations. When the DEMs were resampled to coarser resolutions, the field slope lengths derived from ASTER30m and SRTM90m remained constant, while the one derived from DLG5m increased with plateaus, and reached maximum value $(R E=66.7 \%)$ at $90 \mathrm{~m}$ resolution (Fig. $2 \mathrm{~d}$ ). The mean altitudes and 10 mean areas were not sensitive to resolution in this study (Fig. 2a and C).

Reach lengths and reach slopes varied substantially on resampled resolution, but no trend could be found (Fig. 3a and b). On the other hand reach widths and reach depths were not sensitive to resampled resolutions (Fig. $3 c$ and d). The reach circuits derived from different data sources had obvious biases, even when they were resampled to the same resolution (Fig. 1c).

This resulted in major differences in the topographic features of the estimated reaches. The values of reach lengths, reach widths and reach depths derived from SRTM90m were much higher than those derived from DLG5m and ASTER30m, at the original resolutions or the same resampled resolutions (Fig. 3a, c and d, Table 1). The reach slopes derived from ASTER30m were higher than those derived from DLG5m or SRTM90m at any resampled resolution except for the one of $100 \mathrm{~m}$ (Fig. 3b). The reach slope derived from original ASTER30m (RE=26.5\%) was much higher than those derived from original DLG5m (RE=0\%) and SRTM90m (RE=-1.7\%) (Table 1)

\subsection{SWAT predicted outputs}

25 Comparisons of the REs in the SWAT predictions of outputs indicated that resampled DEM resolutions had a more substantial effect on TPs (Fig. 4c), followed by TNs (Fig. 4d), both of which decreased with coarser resampled resolution; sediments (Fig. 4b) slightly decreased with short-term fluctuation; runoffs (Fig. 4a) did not sensi-

\section{HESSD}

$7,4411-4435,2010$

\section{Effect of DEM resolution on SWAT outputs}

S. Lin et al.

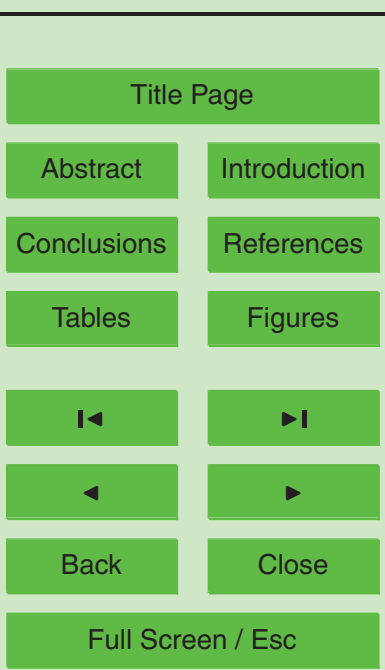

Printer-friendly Version

Interactive Discussion 
tive to resampled resolution.

Table 1 shows the RE variation of predicted outputs variations due to resampled resolutions $\left(R E s_{\max -\min }\right)$. Higher $R E s_{\max -\min }$ for DLG5m indicate that the predicted runoff, sediment, TP, and TN based on DLG5m were more sensitive to resampled 5 resolutions than those based on ASTER30m and SRTM90m (Table 1).

At original resolutions, the predicted runoff, sediment, TP, and TN based on ASTER30m and SRTM90m were similar (less than $2 \%$ of RE difference), whilst the predicted TN and TP based on ASTER30m and SRTM90m were much lower than the one based on DLG5m (Table 1). Runoff and sediment were slightly decreased with o original resolutions (Table 1).

The runoff predictions derived from DLG5m, ASTER30m and SRTM90m were close at any resampled resolution (Fig. 4a), so the predicted accuracy of runoff would not affected by resampling or alternations of DEM source. The sediment predicted accuracies derived from ASTER30m and SRTM90m were close at any resampled resolution, whilst were lower and higher than the one derived from DLG5m at resolutions, respectively finer and coarser than $30 \mathrm{~m}$ (Fig. 4b). At any resampled resolution, the TP and TN predicted accuracies derived from DLG5m always were better than the one derived from SRTM90m, flowed by the one derived from ASTER30m (Fig. 4c and d). For nutrient predictions (TP and TN), which were very sensitive to DEM resolutions, the output accuracies of SWAT derived from ASTER30m and SRTM90m could be improved by down-scaled resampling, but they could not improve on the finer DEM (DLG5m) at the same resolutions.

\section{Discussion}

\subsection{Result justifications}

25 The SCS runoff equation (USDA-SCS, 1972) is used in SWAT2005 runoff calculation. SWAT2005 does not adjust the curve number for slope. In this study, the mean slopes
HESSD

7, 4411-4435, 2010

\section{Effect of DEM resolution on SWAT outputs}

S. Lin et al.

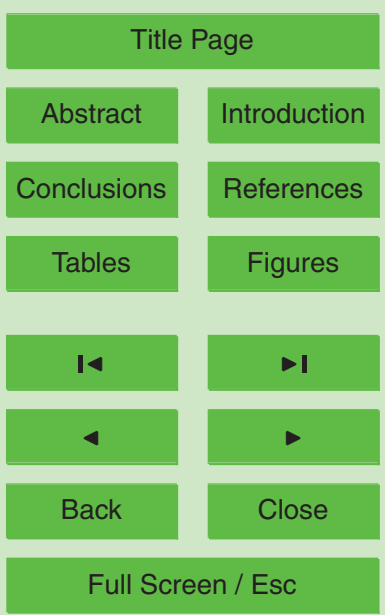

Printer-friendly Version

Interactive Discussion 
apparently decreased with coarser resolution (whether resampled or original), but areas and runoffs were not sensitive to resolutions (Table 1). Results show consistent trends of runoff and area variations on resampling resolutions. The runoffs based on DLG5m, ASTER30m and SRTM90m all slightly decreased or increased with resolu5 tion in the similar way as the areas did, indicating that the changes in runoffs mainly attributed to the changes in areas. Previous studies showed inconsistent results about the effects of original resolutions on SWAT predicted runoffs. Some found that runoff decreased with coarser original DEM resolutions (Wolock and Price, 1994; Cho and Lee, 2001; Di Luzio et al., 2005), some did not (Bosch et al., 2004; Dixon and Earls, 10 2009). However, they all found that mean slope decreased with coarser resolution, which also illustrates that mean slope plays a minor role in runoff output of SWAT. Similar results were found by Chaplot (2005), who resampled DEM from $20 \mathrm{~m}$ to $500 \mathrm{~m}$ and found no regular variation in both area and runoff. In the study of Dixon and Earls (2009), original and resampled DEMs with resolutions of $30 \mathrm{~m}, 90 \mathrm{~m}$, and $300 \mathrm{~m}$ were 15 used as inputs to assess the uncertainty of SWAT. Across the nine runs, larger areas resulted in higher runoffs. Their findings also showed that the variations of the areas were irregular on resolutions, corroborating the irregular variations of this study. However, Cotter et al. (2003) found that the decreases in DEM data resolution (resampled to $30 \mathrm{~m}, 100 \mathrm{~m}, 150 \mathrm{~m}, 200 \mathrm{~m}, 300 \mathrm{~m}, 500 \mathrm{~m}$, and $1000 \mathrm{~m}$ ) resulted in decreased areas and decreased predicted flows, when studying an $18.9 \mathrm{~km}^{2}$ watershed, which is inconsistent with the results of this study. The reason for the difference might be the much larger watershed area in this study. The DEM aggregation may influence the calculated area. However, the direction and extent of the effect will vary upon its base grid size, level of increase, and edge pattern of DEM (Vieux and Needham, 1993). More

variation in area is attributable to more irregular shape as well as smaller area of the watershed (Wu et al., 2008). Therefore, if the predicted runoff is the focus of study, area bias should be considered.

In SWAT, erosion caused by rainfall and surface runoff is computed with the Modified Universal Soil Loss Equation (MUSLE) (Williams, 1972), in which decreased sediment
HESSD

$7,4411-4435,2010$

\section{Effect of DEM \\ resolution on SWAT outputs}

S. Lin et al.

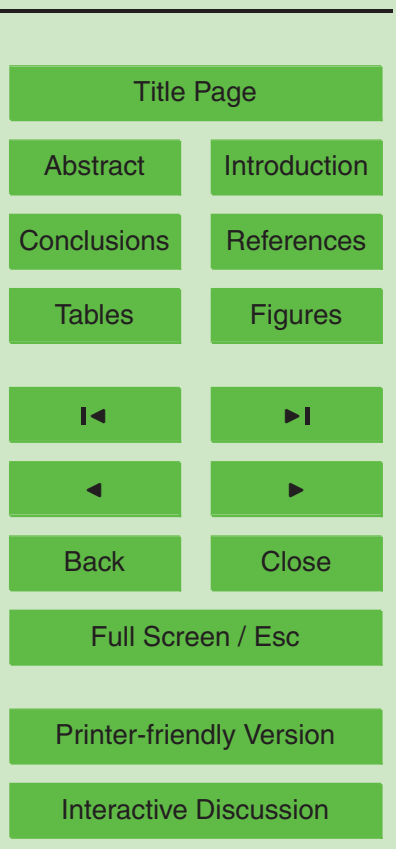


yield from HRU is expected with a decrease in mean slope and field slope length. In this study, the sediments did not decrease as much as the mean slopes and field slope lengths, because sediment channel routing is also simulated in SWAT. The maximum amount of sediment that can be transported from a reach segment is a function of the 5 peak channel velocity, which is calculated using the modified rational formula (USDASCS, 1986) and depends on estimated stream network topographic attributes that are not sensitive to resampled resolutions in this study. The sediment concentrations in the watershed outlet are greatly balanced by the channel degradations and depositions and might be affected by the sediment yield of sub-basins nearby the outlet. Therefore 10 sediments did not decrease as much as slopes with coarser DEM resolution and they were irregularly varied. In the findings of Chaplot (2005), sediment loads predicted by SWAT also varied irregularly on resampled resolution from 20 to $200 \mathrm{~m}$. Other previous studies showed similar results as well (Wolock and Price, 1994; Chaubey et al., 2001; Cotter et al., 2003; Di Luzio et al., 2005).

15 In SWAT, soluble $\mathrm{N}$ and $\mathrm{P}$ in runoff, as products of the volume of water and average concentrations of $\mathrm{N}$ and $\mathrm{P}$ in soil layers, are not sensitive to watershed topographic attributes. But sediment transports of $\mathrm{N}$ and $\mathrm{P}$ are based on the sediment yields in HRUs, which decrease with coarser resolution. The same variation trend shared by slopes and nutrients (TP and TN) in this study indicates that the nutrient outputs are affected by DEM resolution via slope variations. Because most of $P$ is transported by sediment, the decreased gradient of TPs are more than TNs, most of which are transported by water. This result is consistent with those reported by Cotter et al. (2003) and Chaubey et al. (2001), who found that the SWAT simulated TP and $\mathrm{NO}_{3}-\mathrm{N}$ decreased with coarser resampled DEM resolutions from $30 \mathrm{~m}$ to $1000 \mathrm{~m}$. The same trends shared by nutrients (TP and TN) and mean slopes indicate that there should be a parameter to adjust the effects of DEM resolution on SWAT outputs caused by mean slope. The error caused by resampling could be reduced by model calibration. Further analysis of the SWAT output parameters as a function of the DEM resolution input should be the subject of future research.

\section{HESSD}

$7,4411-4435,2010$

\section{Effect of DEM \\ resolution on SWAT outputs}

S. Lin et al.

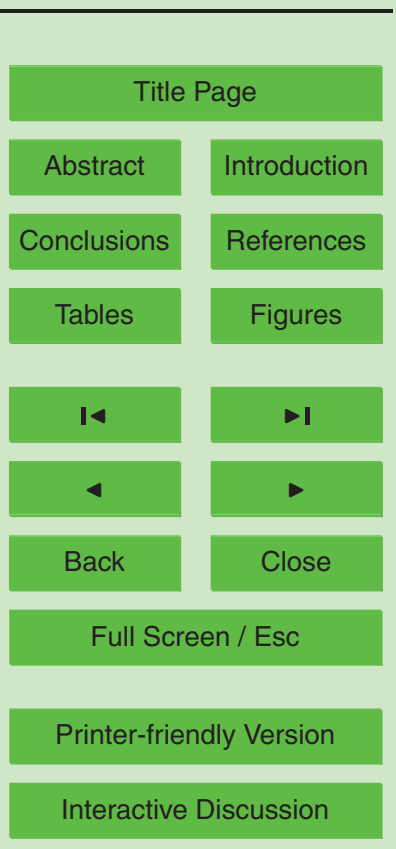




\subsection{DEM resampling}

Resampling is widely used by GIS-based environmental model users to make all raster data layers have the same cell size to facilitate the spatial analysis. For example, when land use/cover or soil is finer than DEM, SWAT users may want to resample the DEM

5 to a finer resolution to keep the accuracy of the finer one. The resolution of GIS data is closely associated to the computation speed in spatial analysis. When the computing time is too long to run a model in high resolution, the SWAT users may want to resample the DEM data to a coarser resolution to speed up the computation procedure.

This study shows that the predicted SWAT outputs of finer DEM (DLG5m) decreased 10 more rapidly than those of coarser DEM (ASTER30m or SRTM90m) for resampled resolution. Resampling coarser DEM input data (ASTER30m or SRTM90m) to higher resolutions could increase the accuracy of the annual predicted TPs and TNs. But the predicted outputs were still much lower than those derived from the finer resolution (DLG5m), indicating that resampling to finer resolutions can make DEMs closer to the 15 real terrain, but their accuracies were still limited by the given resolution of data. It is better to obtain higher resolution DEMs. Whether to resample or not depends on the objective of study. For example, in this study, if annual outputs of runoff and sediment are the foci of the study and $\pm 10.0 \%$ of the maximum RE is allowed, all the predicted outputs are acceptable, based on any resampled resolution from $5 \mathrm{~m}$ to $140 \mathrm{~m}$ for any source of DEM data (Table 1). This result can be helpful for GIS environmental model users in understanding sensitivities of SWAT to the resampled resolutions of DEMs.

\subsection{DEM data quality}

Environmental models often require detailed terrain data. Nowadays, remote sensingderived DEMs form an increasingly important source of information for these applications. Yet it is often not easy to decide what the most feasible source of information is and how differently input data affect model outcomes.

HESSD

$7,4411-4435,2010$

\section{Effect of DEM resolution on SWAT outputs}

S. Lin et al.

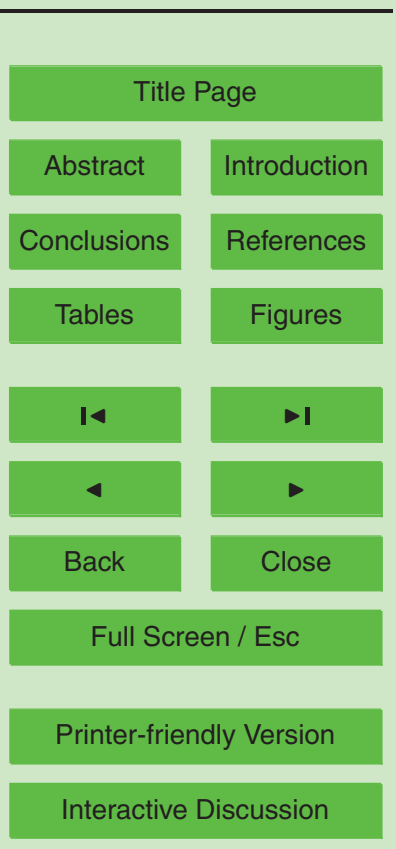


This study compared the quality and performance of remote sensing-derived data (ASTER30m, SRTM90m) for SWAT in a forest watershed in south-eastern China. The results indicate that SWAT predicted outputs, which were based on ASTER30m and SRTM90m, were close to each other. Predicted TN based on SRTM90m performed 5 slightly better than that based on ASTER30m (RE was $-8.2 \%$ for ASTER30m and $-8.0 \%$ for SRTM90m, respectively, see Table 1). It should be no problem to replace the ASTER30m with the coarser SRTM90m in this case, if the annual outputs are the foci of the study and $\pm 10.0 \%$ of the maximum RE is allowed. It should be noted that the estimated reach characteristics based on SRTM90m are substantially different 10 from those based on ASTER30m and DLG5m, so the monthly, and especially the daily predicted outputs might be affected more via channel routing variances, such as peak channel velocity, flow travel time, if monthly of daily predicted outputs are the foci of the study. In this study, the mean slopes of ASTER30m were higher than SRTM90m at any resampled resolution, but the predicted TNs and TPs derived from ASTER30m were 15 not higher than those derived from SRTM90m as expected (Fig. 3). This is explained by the longer reach length, wider reach width, and deeper reach depth of SRTM90m (Fig. 2), which result in lower peak channel velocity, more subsequent sediment deposit in the sub-basin reaches and hence less nutrients in the sediment coming out of the watershed.

20 De Vente et al. (2009) found that SRTM90m provided more accurate estimates of slope gradient and upslope drainage area than the ASTER30m in the 14 Spanish catchments. Our study shows that SRTM90m provided a little more accurate estimate of area but a little less accurate estimate of mean slope than the ASTER30m (Table 1). The differences in these results might be caused by the different accuracies of different study areas. Blanchard et al. (2010) summarized the vertical accuracy of ASTER30m and SRTM90m, and indicated that SRTM90m vertical accuracies were the highest for built-up area and bare soil, and the lowest for forest, which domains the land use/cover of this study area, whereas ASTER30m accuracies were the highest for forest and the lowest for agriculture and grassland land cover. What is more, the indi-
HESSD

$7,4411-4435,2010$

\section{Effect of DEM \\ resolution on SWAT outputs}

S. Lin et al.

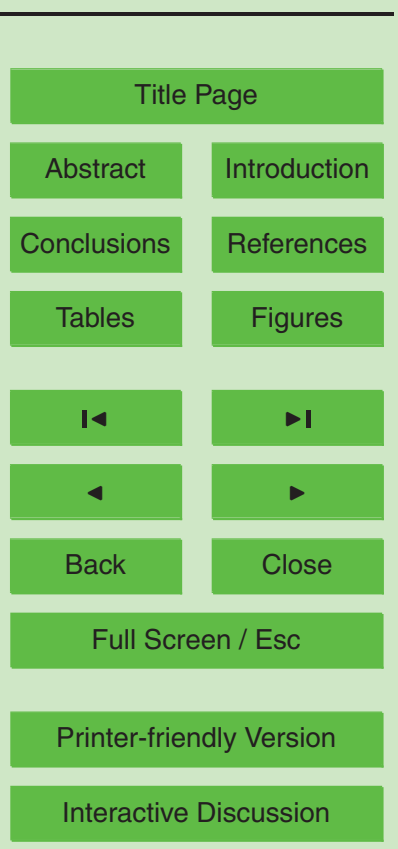


vidual scene DEMs that were stacked to create the final averaged DEM elevation value also affect the accuracy of ASTER30m or SRTM90m. Higher accuracy contributed by more scene DEMs. The number of scenes stacked is different in different positions. Therefore, to evaluate the effects of different source DEMs (ASTER30m or SRTM90m) 5 on SWAT outputs, more future studies considering the variations of the data accuracy for different study areas and land use/cover are necessary.

\section{Summary}

This study evaluated the effect of DEM resolutions on SWAT outputs using DLG5m, ASTER30m, and SRTM90m. Up-scaled resampling simplified the terrain characteris10 tics. Some of the watershed delineation variables as the parameters of SWAT were affected by resampling. The mean slopes decreased significantly on coarser resampled resolution. Sequentially, the field slopes lengths and reach slopes were also affected. DEM grid aggregation caused variations in grid-based area and distance. Therefore, watershed areas, reach widths, and reach depths fluctuated on resampled resolution. 15 But the fluctuations were minor comparing to the decrease in mean slopes.

When resampling DEM to a coarser resolution, SWAT predicted lower outputs of TPs, TNs, and sediments. Runoffs were not sensitive to resample resolution in SWAT2005. Model calibration might be able to reduce the error caused by resampling.

The SWAT predicted outputs of runoff, sediment, TP, and TN based on ASTER30m and SRTM90m in this study were close, which did not mean that ASTER30m and SRTM90m generated similar accuracy, because land use/cover and the individual scene DEMs that were stacked to create the final averaged DEM elevation value also affected the accuracies of remote sensing-derived DEMs (ASTER30m and SRTM90m).

Acknowledgements. Funding of this study was provided partly by National Key Project for Wa25 ter Research (Grant No. 2008ZX07101-006). We sincerely appreciate Stefan Fritsch and GBP Huddlestone for their helps on language improvement of this manuscript.

\section{HESSD}

$7,4411-4435,2010$

\section{Effect of DEM resolution on SWAT outputs}

S. Lin et al.

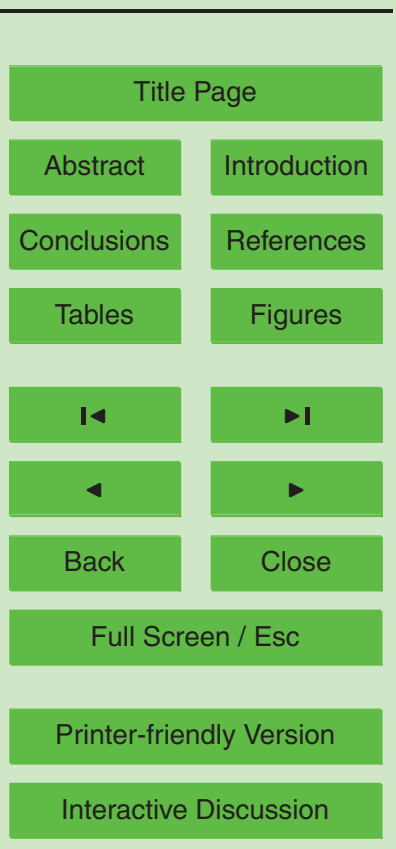

Interactive Discussion 


\section{References}

Arnold, J. G., Srinivasan, R., Muttiah, R. S., and Williams, J. R.: Large area hydrologic modeling and assessment - part 1: model development, J. Am. Water Resour. As., 34, 73-89, 1998.

Blanchard, S. D., Rogan, J., and Woodcock, D. W.: Geomorphic change analysis using ASTER and SRTM digital elevation models in Central Massachusetts, USA, Gisci. Remote Sens., 47, 1-24, doi:10.2747/1548-1603.47.1.1, 2010.

Bosch, D. D., Sheridan, J. M., Batten, H. L., and Arnold, J. G.: Evaluation of the swat model on a coastal plain agricultural watershed, Trans. ASAE, 47, 1493-1506, 2004.

Chaplot, V.: Impact of dem mesh size and soil map scale on swat runoff, sediment, and $\mathrm{NO}_{3}-\mathrm{N}$ loads predictions, J. Hydrol., 312, 207-222, 10.1016/j.jhydrol.2005.02.017, 2005.

Chaubey, I., Cotter, A. S., Costello, T. A., and Soerens, T. S.: Effect of dem data resolution on swat output uncertainty, 1st International SWAT Conference, Rauischholzhausen, 2001, ISI:000227231300005, 621-628,

Chaubey, I., Cotter, A. S., Costello, T. A., and Soerens, T. S.: Effect of dem data resolution on swat output uncertainty, Hydrol. Process., 19, 621-628, 10.1002/hyp.5607, 2005.

Chen, D. J., Lu, J., Wang, H. L., Shen, Y. N., and Kimberley, M. O.: Seasonal variations of nitrogen and phosphorus retention in an agricultural drainage river in East China, Environ. Sci. Pollut. Res., 17, 312-320, 10.1007/s11356-009-0246-x, 2010.

Cheng, H. G., Ouyang, W., Hao, F. H., Ren, X. Y., and Yang, S. T.: The non-point source pollution in livestock-breeding areas of the Heihe River Basin in Yellow River, Stoch. Env. Res. Risk A., 21, 213-221, doi:10.1007/s00477-006-0057-2, 2007.

Cho, S. M. and Lee, M.: Sensitivity considerations when modeling hydrologic processes with digital elevation model, J. Am. Water Resour. As., 37, 931-934, 2001.

Cotter, A. S., Chaubey, I., Costello, T. A., Soerens, T. S., and Nelson, M. A.: Water quality model output uncertainty as affected by spatial resolution of input data, J. Am. Water Resour. As., 39, 977-986, 2003.

de Vente, J., Poesen, J., Govers, G., and Boix-Fayos, C.: The implications of data selection for regional erosion and sediment yield modelling, Earth Surf. Proc. Land., 34, 1994-2007, doi:10.1002/esp.1884, 2009.

30 Di Luzio, M., Srinivasan, R., and Arnold, J. G.: A GIS-coupled hydrological model system for the watershed assessment of agricultural nonpoint and point sources of pollution, Trans. GIS, 8, 113-136, 2004.
HESSD

7, 4411-4435, 2010

\section{Effect of DEM resolution on SWAT outputs}

S. Lin et al.

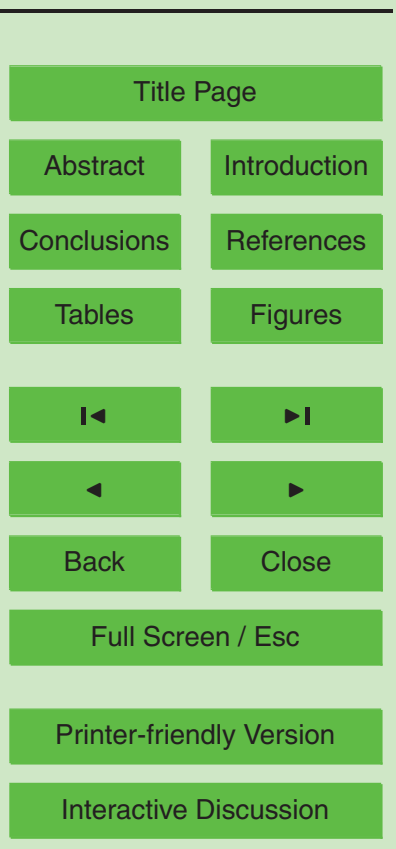


Di Luzio, M., Arnold, J. G., and Srinivasan, R.: Effect of gis data quality on small watershed stream flow and sediment simulations, Hydrol. Process., 19, 629-650, doi:10.1002/hyp.5612, 2005.

Dixon, B. and Earls, J.: Resample or not?! Effects of resolution of dems in watershed modeling, Hydrol. Process., 23, 1714-1724, doi:10.1002/hyp.7306, 2009.

Gassman, P. W., Reyes, M. R., Green, C. H., and Arnold, J. G.: The soil and water assessment tool: Historical development, applications, and future research directions, Trans. ASABE, 50, 1211-1250, 2007.

Green, W. H. and Ampt, G. A.: Studies on soil physics part 1 - the flow of air and water through soils, J. Agr. Sci., 4, 1-24, 1911.

He, H. M., Zhou, J., and Zhang, W. C.: Modelling the impacts of environmental changes on hydrological regimes in the Hei River Watershed, China, Global Planet. Change, 61, 175193, doi:10.1016/j.gloplacha.2007.08.012, 2008.

Lai, G. Y., Yu, G., and Gui, F.: Preliminary study on assessment of nutrient transport in the

15 Taihu Basin based on swat modeling, Sci. China Ser. D, 49, 135-145, doi:10.1007/s11430006-8113-9, 2006.

Li, Z., Liu, W. Z., Zhang, X. C., and Zheng, F. L.: Impacts of land use change and climate variability on hydrology in an agricultural catchment on the loess plateau of China, J. Hydrol., 377, 35-42, doi:10.1016/j.jhydrol.2009.08.007, 2009a.

$20 \mathrm{Li}, \mathrm{Z}$. L., Xu, Z. G., Shao, Q. X., and Yang, J.: Parameter estimation and uncertainty analysis of swat model in upper reaches of the Heihe River Basin, Hydrol. Process., 23, 2744-2753, doi:10.1002/hyp.7371, 2009b.

Ma, X., Xu, J. C., Luo, Y., Aggarwal, S. P., and Li, J. T.: Response of hydrological processes to land-cover and climate changes in Kejie Watershed, South-West China, Hydrol. Process., 23, 1179-1191, doi:10.1002/hyp.7233, 2009.

McElroy, A. D., Chiu, S. Y., Nebgen, J. W., Aleti, A., and Bennett, F. W.: Loading functions for assessment of water pollution from nonpoint sources, in: EPA document EPA 600/2-76-151, USEPA, Athens, GA, 1976.

Neitsch, S. L., Arnold, J. G., Kiniry, J. R., Srinivasan, R., and Williams, J. R.: Soil and water assessment tool input/output file documentation version 2005, Temple, Texas, 530 pp., 2005.

Ouyang, W., Hao, F. H., Wang, X. L., and Cheng, H. G.: Nonpoint source pollution responses simulation for conversion cropland to forest in mountains by swat in China, Environ. Manage., 41, 79-89, doi:10.1007/s00267-007-9028-8, 2008.
HESSD

$7,4411-4435,2010$

\section{Effect of DEM \\ resolution on SWAT \\ outputs}

S. Lin et al.

Title Page

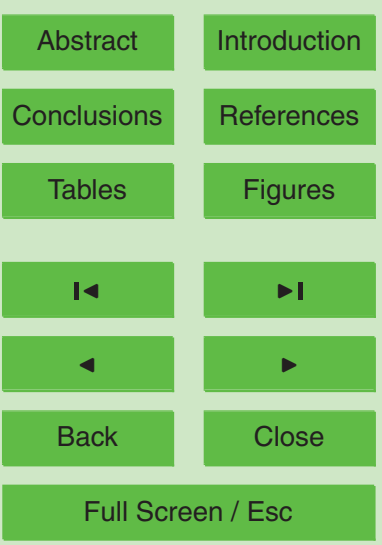

Printer-friendly Version

Interactive Discussion 
USDA-SCS: National Engineering Handbook, Hydrology Sect. 4, Chapters 4-10, US Department of Agriculture, Soil Conservation Service, 1972.

USDA-SCS: Urban hydrology for small watersheds. Tech. Release 55, US Dept. of Agriculture, Soil Conservation Service, Washington, DC, USA, 1986.

5 Vieux, B. E. and Needham, S.: Nonpoint-pollution model sensitivity to grid-cell size, J. Water Res. Plan. Manage.-ASCE, 119, 141-157, 1993.

Wang, S. F., Kang, S. Z., Zhang, L., and Li, F. S.: Modelling hydrological response to different land-use and climate change scenarios in the Zamu River Basin of Northwest China, Hydrol. Process., 22, 2502-2510, doi:10.1002/hyp.6846, 2008.

10 Wei, X.: Records of Soil Species in Zhejiang, edited by: Office, Z. S. S., Zhejiang Science and Technology Press, Hangzhou, China, 1993.

Williams, J. R.: Sediment-yield prediction with universal equation using runoff energy factor, Present and prospective technology for predicting sediment yield and sources: Proceedings of the sediment-yield workshop, Oxford, MS, 1972, 244-252, 1975.

Williams, J. R. and Hann, R. W.: Optimal operation of large agricultural watersheds with water quality constraints, in: Texas Water Resources Institute, Texas A\&M Univ., Tech. Rept. No. 96, 1978.

Winchell, M., Srinivasan, R., Di Luzio, M., and Arnod, J.: Arcswat 2.3 interface for swat2005 user's guide, Temple, Texas, 476 pp., 2005.

20 Wolock, D. M. and Price, C. V.: Effects of digital elevation model map scale and data resolution on a topography-based watershed model, Water Resour. Res., 30, 3041-3052, 1994.

Wu, S., Li, J., and Huang, G. H.: A study on dem-derived primary topographic attributes for hydrologic applications: Sensitivity to elevation data resolution, Appl. Geogr., 28, 210-223, doi:10.1016/j.apgeog.2008.02.006, 2008.

Xu, Z. X., Pang, J. P., Liu, C. M., and Li, J. Y.: Assessment of runoff and sediment yield in the Miyun reservoir catchment by using swat model, Hydrol. Process., 23, 3619-3630, doi:10.1002/hyp.7475, 2009.

Yu, G., Xue, B., Lai, G. Y., Gui, F., and Liu, X. M.: A 200-year historical modeling of catchment nutrient changes in Taihu Basin, China, Hydrobiologia, 581, 79-87, doi:10.1007/s10750006-0514-4, 2007.

Zhang, Q. L., Chen, Y. X., Jilani, G., Shamsi, I. H., and Yu, Q. G.: Model avswat apropos of simulating non-point source pollution in Taihu Lake Basin, J. Hazard. Mater., 174, 824-830, doi:10.1016/j.jhazmat.2009.09.127, 2010.

HESSD

7, 4411-4435, 2010

\section{Effect of DEM resolution on SWAT outputs}

S. Lin et al.

Title Page

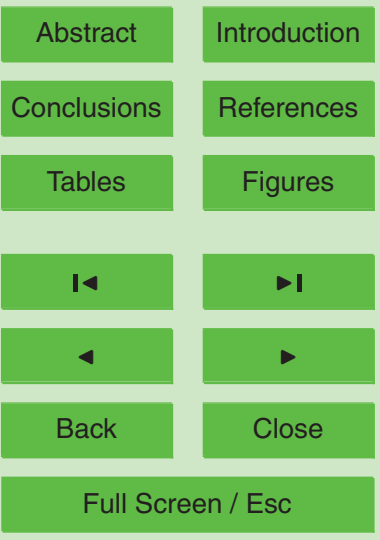

Printer-friendly Version

Interactive Discussion 


\section{HESSD}

$7,4411-4435,2010$

\section{Effect of DEM resolution on SWAT outputs}

\begin{tabular}{lrrrrrr}
\hline Variable & $\mathrm{RE}_{\max }$ min & & & $\mathrm{RE}_{\text {original }}$ & \\
& DLG5m & ASTER30m & SRTM90m & DLG5m & ASTER30m & SRTM90m \\
\hline Mean altitude & 0.4 & 0.1 & 0.2 & 0 & 0.8 & -0.4 \\
Mean slope & 40.0 & 12.8 & 13.2 & 0 & -32.1 & -37.2 \\
Area & 1.2 & 0.3 & 0.3 & 0 & 0.5 & 0.2 \\
Field slope length & 66.7 & 0.0 & 0.0 & 0 & 66.7 & 66.7 \\
Reach length & 10.5 & 3.8 & 5.2 & 0 & -10.5 & 18.2 \\
Reach slope & 14.1 & 20.8 & 7.3 & 0 & 25.6 & -1.7 \\
Reach width & 1.5 & 0.6 & 0.4 & 0 & 0.6 & 14.3 \\
Reach depth & 0.9 & 0.4 & 0.2 & 0 & 0.4 & 9.5 \\
Runoff & 1.0 & 0.5 & 0.3 & 0 & -0.3 & -0.8 \\
Sediment & 6.0 & 2.9 & 2.9 & 0 & -1.7 & -3.0 \\
TP & 23.0 & 9.9 & 10.9 & 0 & -17.2 & -18.3 \\
TN & 11.3 & 5.2 & 5.8 & 0 & -8.2 & -8.0 \\
\hline
\end{tabular}

Note: $R E_{\max -\min }$ : the relative error $(\mathrm{RE})$ variation (maximum-minimum) due to resampled resolutions. $\mathrm{RE}_{\text {original }}$ : $\mathrm{RE}$ at original resolution.

S. Lin et al.

Title Page

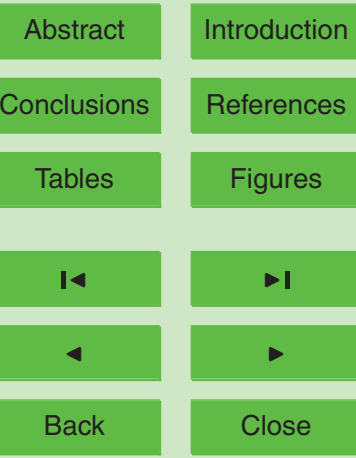

Full Screen / Esc

Printer-friendly Version

Interactive Discussion 

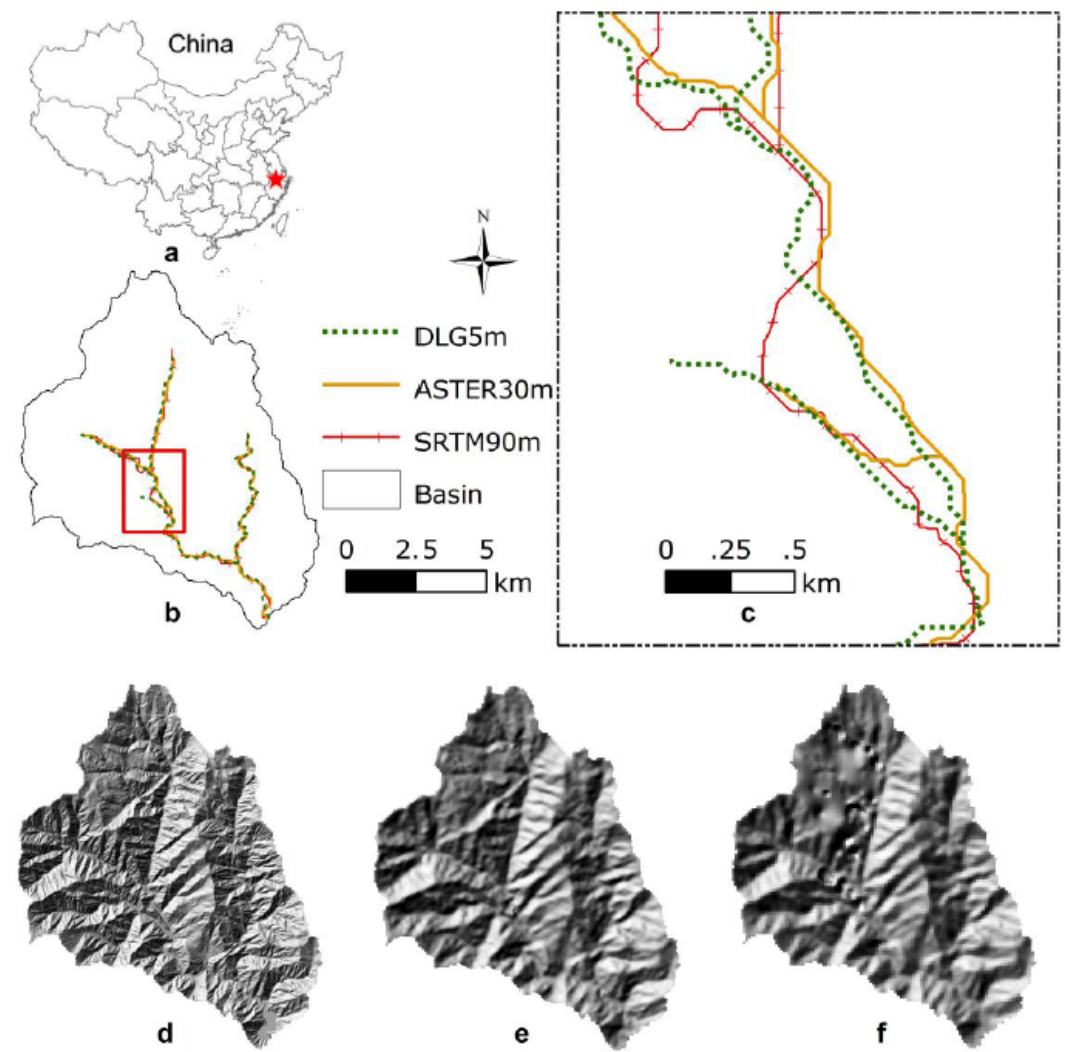

Fig. 1. (a) Location of the Xiekengxi River watershed $\left(81.7 \mathrm{~km}^{2}\right)$; (b) estimated stream networks derived from different DEMs (ASTER30m and SRTM90m were resampled to the same resolution $5 \mathrm{~m}$ as DLG5m for comparison); (c) stream networks zooming in on the rectangle of b; (d-f) shaped terrain derived from original DEM of DLG5m, ASTER30m, and SRTM90m, respectively.

\section{HESSD}

$7,4411-4435,2010$

\section{Effect of DEM resolution on SWAT outputs}

S. Lin et al.

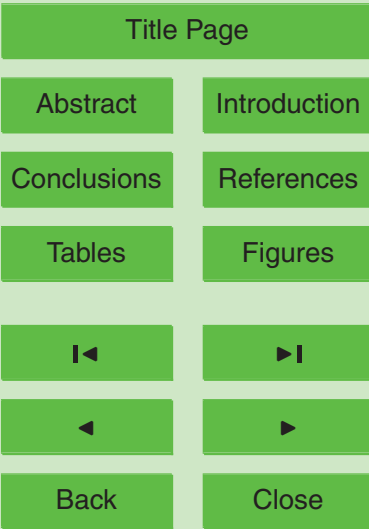

Full Screen / Esc

Printer-friendly Version

Interactive Discussion 


\section{HESSD}

$7,4411-4435,2010$
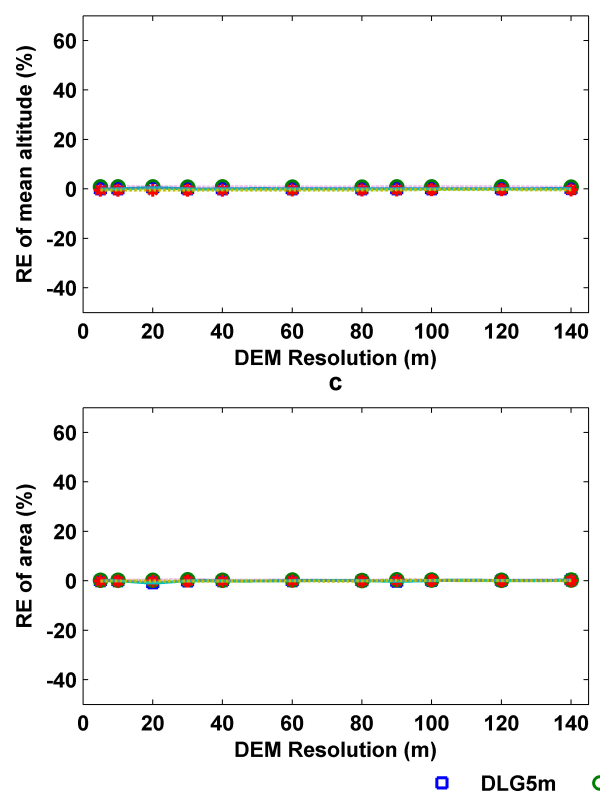
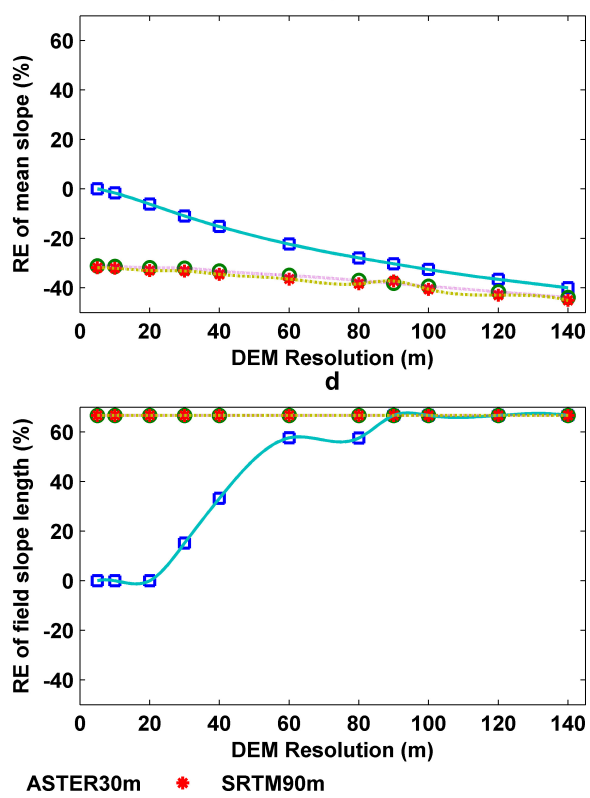

ASTER30m * SRTM90m

Fig. 2. The effects of DEM resolution on watershed topographic characteristics. Relative errors (REs) were calculated based on the values derived from the finest DEM (DLG5m). Lines between data points are cubic interpreting trend lines.

\section{Effect of DEM resolution on SWAT outputs}

S. Lin et al.

\section{Title Page}

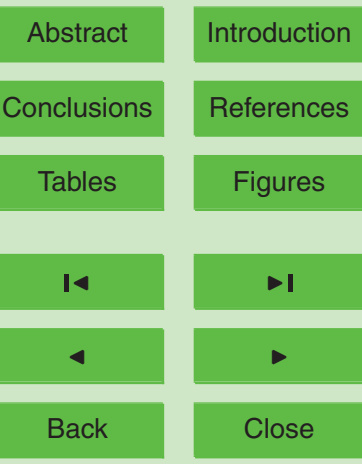

Full Screen / Esc

Printer-friendly Version

Interactive Discussion 


\section{HESSD}

$7,4411-4435,2010$
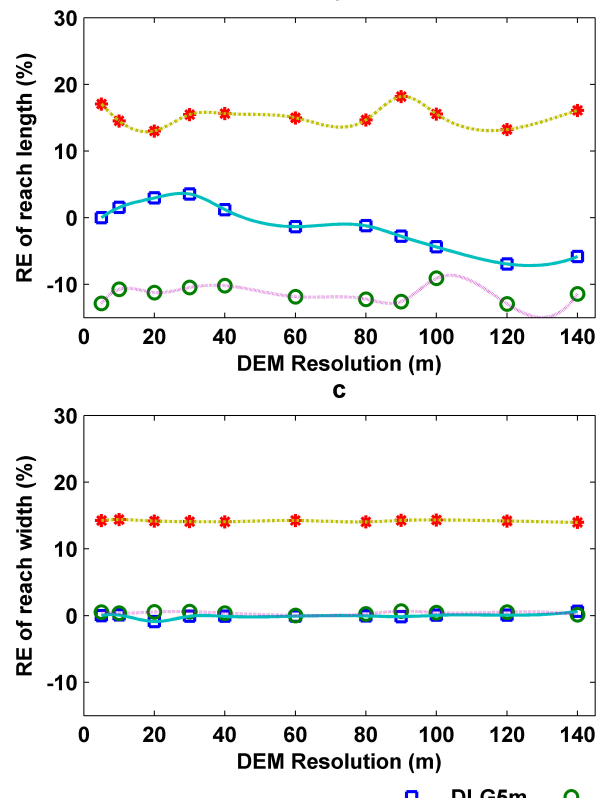

o DLG5m
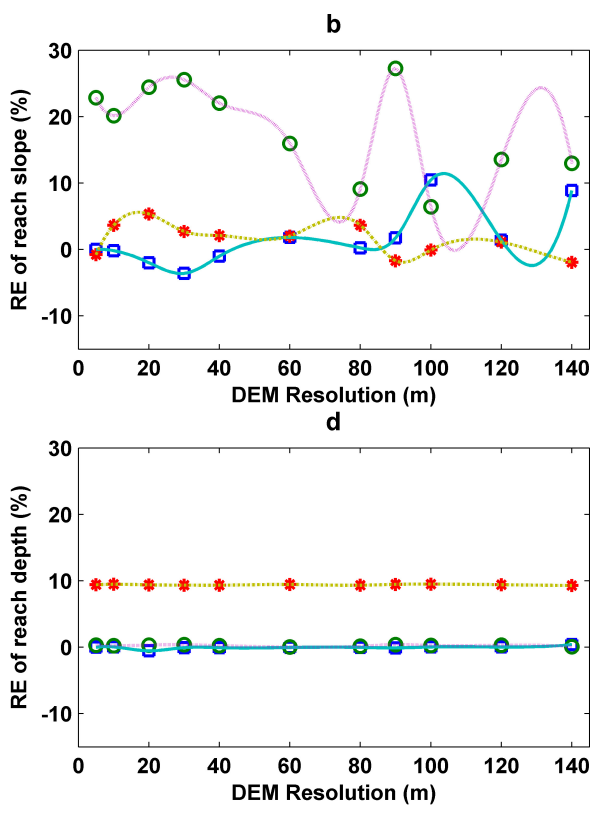

ASTER30m * SRTM90m

Fig. 3. The effects of DEM resolution on estimated stream network characteristics. Relative errors (REs) were calculated based on the values derived from the finest DEM (DLG5m). Lines between data points are cubic interpreting trend lines.

\section{Effect of DEM resolution on SWAT outputs}

S. Lin et al.

Title Page

Abstract

Introduction

Conclusions

References

Tables

Figures

14

$\rightarrow 1$

4

Back

Close

\section{Full Screen / Esc}

Printer-friendly Version

Interactive Discussion 


\section{HESSD}

$7,4411-4435,2010$
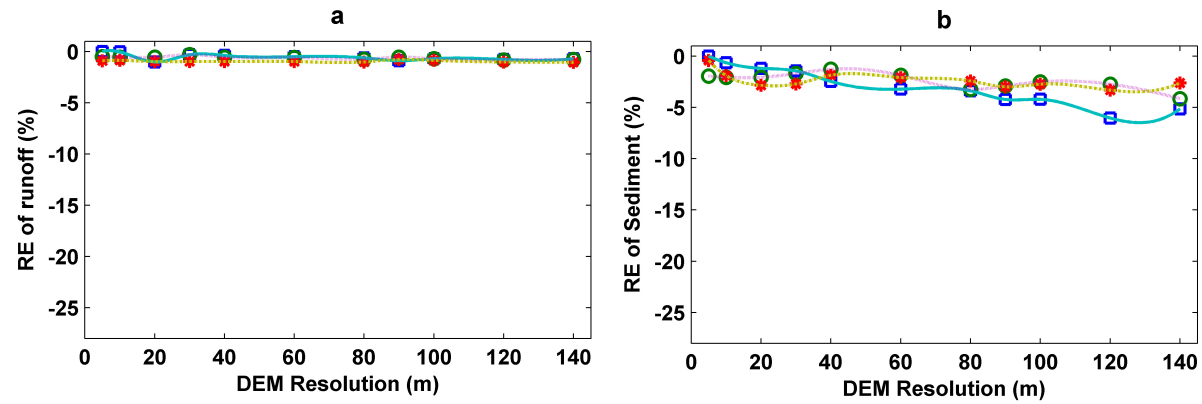

d
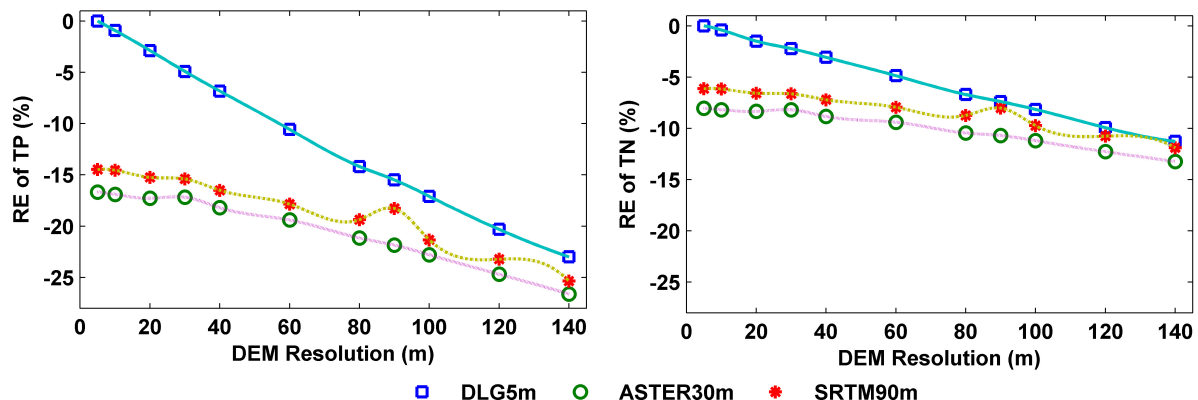

口 DLG5m O ASTER30m * SRTM90m

Fig. 4. The effects of DEM resolution on SWAT predicted outputs. Relative errors (REs) were calculated based on the values derived from the finest DEM (DLG5m). Lines between data points are cubic interpreting trend lines.

\section{Effect of DEM resolution on SWAT outputs}

S. Lin et al.

Title Page

Abstract

Introduction

Conclusions

References

Tables

Figures

14

4

Back

Close

\section{Full Screen / Esc}

Printer-friendly Version

Interactive Discussion 